\title{
Mesenchymal Stem Cell Therapy for Cardiac Repair
}

\author{
Rahul Thakker, BS* and Phillip Yang, MD \\ Division of Cardiovascular Medicine, Department of Medicine, Stanford University, Stanford, CA, \\ USA
}

\section{Keywords}

Heart disease; Cardiac injury; Mesenchymal stem cell therapy; Transplantation

\section{Introduction}

Approximately every 34 seconds, an American suffers a coronary event [1]. These events typically result in myocardial infarction (MI), which is characterized by myocyte necrosis because of oxygen deprivation and leads, subsequently, to the formation of a fibrous scar in the heart [2]. The loss of cardiac muscle can lead to ventricular remodeling in response to injury and ischemic cardiomyopathy (ICM) over time [3-5]. Though remodeling has been shown to maintain or even improve stroke volume [3,4] and, therefore, cardiac output, [5] the cost is significant dilatation of the left ventricle (LV) to increase chamber volume and compensate for the lost myocardium [3-5]. Progressive enlargement of the LV causes an eventual decline in ejection fraction $[3,5]$ and is associated with poor long-term prognosis, including onset of heart failure (HF) [5] and a decrease in survival [6]. All told, one of every six deaths in the United States is due to coronary artery disease while one of every nine involves HF, [1] yet few therapies, whether medical, surgical, or mechanical, exist that can prevent or reverse LV dilatation after MI [7]. For that reason, the idea of cell-based therapy for cardiac repair has gained popularity, and numerous cell types, from embryonic stem cells (ESCs) to cardiac progenitor cells [8] have been studied to assess their ability to regenerate viable, functional myocardial tissue. For this article, we will focus on mesenchymal stem cells (MSCs) as these cells have gained significant popularity in recent years.

\section{Definition of MSC}

MSCs were first identified in the 1960s when Friedenstein discovered a sub-population of bone marrow (BM) cells that adhered to plastic, had a fibroblast-like appearance [9•], and formed clonal colonies in vitro [10]. He also demonstrated that in vivo transplantation of these cells led to the generation of multiple skeletal tissues from the progeny of a single

\footnotetext{
(c) Springer Science+Business Media New York 2014

*rthakker@stanford.edu.

Conflict of Interest

Rahul Thakker and Dr. Phillip Yang each declare no potential conflicts of interest.

Human and Animal Rights and Informed Consent

This article does not contain any studies with human or animal subjects performed by any of the authors.
} 
precursor, which he called an osteogenic stem cell [11] or BM stromal stem cell [12]. The term MSC was not used until it was coined by Caplan in 1991 [13]. MSCs have since been found in several different tissue types including skin, fat, muscle, ligament, tendon, umbilical cord, and placenta, among others [14]. This heterogeneity has made it difficult to establish a precise definition of MSCs. Unlike hematopoietic stem cells, MSCs lack a unique cell surface marker. Instead it has been proposed that cells must meet the following criteria in order to be classified as MSCs [15]: (1) they must be plastic-adherent when cultured under standard conditions; (2) they must express CD105, CD73, and CD90 but lack expression of CD45, CD34, CD14 or CD11b, CD79a or CD19, and HLA-DR; and (3) they must differentiate into osteoblasts, adipocytes, and chondroblasts in vitro. It was this third trait - the ability to differentiate into a variety of mesodermal lineages-that made MSCs a promising target for tissue regeneration and engineering.

\section{Why MSCs?}

Although the function of MSCs in vivo is not fully understood, it is thought that they are responsible primarily for the normal turnover and maintenance of adult mesenchymal tissues [16]. The ability of MSCs to both self-renew and differentiate makes them an ideal source of replacement cells [17]. For example, human MSCs injected into the LV of an adult murine heart engraft in the myocardium and become morphologically indistinguishable from the native cardiomyocytes (CMs) [18]. MSCs also promote the growth and proliferation of neighboring cells through paracrine signaling. MSC-derived conditioned medium has previously been shown to activate cardiac progenitor cells in vitro, leading to enhanced migration, upregulation of CM-related genes, and inhibition of apoptosis under hypoxia and serum starvation [19]. The mechanism responsible for the beneficial effects of MSCs, however, remains to be clarified. Interestingly, Hatzistergos et al. [20] published data from an in vivo swine study suggesting that conditioned medium alone may not be enough to stimulate proliferation of ${\mathrm{c}-\mathrm{kit}^{+}}^{+}$cardiac stem cells (CSCs) and that the cells themselves are necessary for the recruitment of new CMs. One key issue that needs to be addressed as soon as possible is that while MSCs are known to secrete a broad spectrum of regulatory and trophic factors including growth factors, cytokines, and chemokines, characterization of this secretome has been limited [21]. One molecule that seems to be made constitutively by MSCs is vascular endothelial growth factor (VEGF), suggesting a role in angiogenesis and vasculogenesis [22-24]. This finding is further supported by the observations that MSCs release greater levels of VEGF when subjected to hypoxic conditions [23] and that transplantation of MSCs into murine hindlimb ischemia [23] or MI [25] models led to an increase in vessel density. Considering cell death after MI is due to lack of oxygenated blood flow [2], this property of MSCs makes them extremely valuable when attempting to repopulate an infarct area with viable CMs.

In addition to its capacity to facilitate cellular growth and proliferation, the paracrine signaling of MSCs functions in wound healing and modulation of the immune system. Evidence suggests that MSCs have the ability to enter the circulation and follow chemotactic gradients to home to sites of injury or inflammation [26-29]. MSCs may regulate the development of fibroblasts and endothelial cells, a process that is commonly involved in tissue repair, through the release of growth factors, as a source of extracellular matrix, and 
as a catalyst for angiogenesis [30,31]. MSCs simultaneously create an immunosuppressive microenvironment to mitigate inflammatory response [26, 30, 32]. In a healthy individual, acute tissue injury will lead to the activation of many kinds of immune cells including macrophages, B and T lymphocytes, dendritic cells, and natural killer cells; however, an excessive response can actually interfere with repair or even exacerbate the damage [30]. In the presence of inflammatory cytokines such as interferon- $\gamma$, tumor necrosis factor- $\alpha$, and interleukin-1 $\beta$ [30], MSCs release soluble factors that counteract the activation, proliferation, and maturation of the cells that carry out both adaptive and innate immunity $[26,33]$. Administration of the immunosuppressive drug cyclosporin-A has long been known to reduce infarct size by inhibiting the activation of leukocytes by ischemic tissue; $[34,35]$ however, treatment with anti-inflammatory drugs post-MI has led to catastrophic LV free wall rupture, suggesting the need for an inflammatory response to mediate wound healing. Although MSCs demonstrate a clear effect on the immune system, interestingly, they themselves escape recognition by their targets. MSCs do not display immunogenic surface markers like major histocompatibility complex (MHC) antigens or other costimulatory molecules, and, therefore, elicit a much smaller immune reaction [26, 32, 33]. This relative immunoprivileged status permits allogeneic transplantation of MSCs without the usual concern of rejection, an advantage that would allow for more timely treatment using an off-the-shelf stock of prepared cells should MSC therapy prove to be effective.

\section{Clinical research}

MSC research in animals like rodents and swine has been well documented for decades, but the quest to determine the efficacy of MSCs in human cardiac repair is just now beginning. Hare et al. [36•] performed one of the first major MSC therapy trials, a phase I, randomized, double-blinded, placebo-controlled test of allogeneic BM-derived MSCs (BM-MSCs) in patients with acute MI ( $n=53)$. The cells were administered intravenously up to 10 days post-MI at one of three doses. This study not only endorsed the safety of MSCs, but also found that the MSC-treated groups experienced fewer arrhythmias and improved left ventricular ejection fraction (LVEF) that was sustained 6 months after treatment. These findings led to a subsequent phase II study $(\mathrm{n}=220)$ for which the data is as yet unpublished but preliminary reports have stated that an infusion of MSCs within 7 days of acute MI significantly reduced cardiac hypertrophy, arrhythmia, progression to HF, and rehospitalization for cardiac complications [37]. Hare's team also conducted the phase I/II randomized percutaneous stem cell injection delivery effects on neomyogenesis (POSEIDON) trial [38] with the purpose of comparing autologous and allogeneic BMMSCs in the treatment of ICM. Though the study was limited by a lack of a placebo control and a small participant population $(n=30)$, the results were encouraging. Injected transendocardially, both autologous and allogeneic MSCs showed equally low rates of adverse events and were associated with reversal of LV remodeling, reduction in myocardial scarring, and better quality of life. Although various trials have studied MSCs "as is," others such as the cardiopoietic stem cell therapy in heart failure (C-CURE) study [39] have examined the differentiative potential of these cells. Autologous BM-MSCs were primed with a cardiogenic growth-factor cocktail prior to endomyocardial injection in patients with chronic HF $(n=45)$ who were not randomized to standard medical care. The hope was that 
lineage-selected sub-populations of MSCs would contain a higher percentage of cells of a favorable phenotype, thereby, increasing the amount of engraftment and retention, and after 6 months of follow-up the intervention cohort indeed showed improvement in the 6-minute walk test and LVEF as well as a decrease in end-systolic volumes. Nevertheless, further data would likely be required to confidently assert that cardiopoietic MSCs convey an advantage over their natural relatives. Perhaps ongoing or upcoming trials including randomized clinical trial of adipose-derived stem cells in the treatment of patients with ST-elevation myocardial infarction (APOLLO) and safety and efficacy of adipose derived regenerative cells delivered via the intracoronary route in the treatment of patients with ST-elevation acute myocardial infarction (ADVANCE) [40], which are studying adipose tissue-derived MSCs (AT-MSCs) in patients with ST-segment elevation MI; mesenchymal stromal cell therapy in patients with chronic myocardial ischemia (MyStromalCell) [41], which is investigating the effects of VEGF-stimulated AT-MSCs on chronic ischemic heart disease and refractory angina; and allogeneic mesenchymal precursor cell infusion in myocardial infarction (AMICI) [42], which is assessing the safety of intracoronary injections of MSC precursors into patients undergoing left anterior descending revascularization after acute MI, will help to provide more clarity regarding the optimal origin, delivery method, and pretreatment strategy for therapeutic MSCs.

\section{Reprogramming human amniotic mesenchymal stem cells into induced pluripotent stem cells}

The initial success of these clinical trials suggests MSCs may in fact become the foundation for regenerative medicine in the future. However, the restorative potential of the CMs derived from reprogrammed MSCs was examined recently. This possibility has become the driving force behind the use of iPSC technology to generate cardiac cells in vitro. Ge et al. [43•] reported the ability to reprogram human amniotic mesenchymal stem cells (hAMSCs) into iPSCs, which is robustly differentiated into CMs. In addition to the immunomodulatory properties and cardiac differentiation potential associated with all MSCs, these cells displayed high reprogramming efficiency due to their partial pluripotency and began to form hAMSC-derived iPSC (MiPSC) colonies within ten days of transduction with the four Yamanaka factors: Sox2, Klf4, Oct4, and cMyc [44]. An important finding was that while MiPSCs displayed features typical of H7 ESCs, they retained the immunoprivileged state of hAMSCs as characterized by expression of HLA-G and CD59 but lack of MHC classes I or II (also known as HLA-C and HLA-DR, respectively) [43•]. Furthermore, over $50 \%$ of MiPSCs were found, through flow cytometry, to express the c-kit surface marker, which is considered an indicator of precardiac mesodermal progenitor cells. This sub-population underwent cardiac differentiation and exhibited spontaneous contractility, with more than 60 $\%$ of the cells beating by day 28 , and the CM phenotype was confirmed by the upregulation of cardiac specific genes, including Nkx2.5, Gata-4, and cardiac troponin T [43•]. Proposed animal studies involving this method have high expectations because fibroblast-derived iPSCs in murine models have reversed LV remodeling and restored function post-MI [45] and hAMSCs themselves have displayed substantial therapeutic effect because of their precardiac properties as well as their engraftment and survival capacity [25]. 


\section{Future directions}

MSC transplantation appears to be a powerful tool in regenerative medicine, but there remain questions that must be answered before it can be recognized as an established treatment for cardiac repair. First and foremost, we must demonstrate that MSCs are the optimal cells to achieve significant restoration and not just transient improvement. This is still uncertain as it was recently published that CSCs, either alone [46] or combined with MSCs [47], may be more effective to reduce infarct area and vascular afterload because of their enhanced engraftment potential. There also remain concerns regarding not only the mechanism and degree of benefit of MSC therapy, but also its potential for harm. Even though the majority of studies indicate that MSCs are in fact safe, there is literature to support the claim that they can increase the risk of adverse effects. According to past in vitro experiments, MSCs in long-term culture demonstrate chromosomal instability and are susceptible to spontaneous malignant transformation [48-51]. However, the findings published by Rubio et al. [48] and Rosland et al. [49] turned out to be due to contamination of the MSC culture with a cancerous line [52], making it hard to gauge the validity of the other papers. Nevertheless, because MSCs are multipotent their tumorigenic capacity must be evaluated and strict regulations must be put in place with regards to the handling of these cells [53]. The differentiative ability of MSCs also brings up another issue: the formation of bone, cartilage, or other mesenchymal tissues at ectopic sites. To date, there have been no reports of ectopic tissue formation in vivo in clinical trials [54], but animal research has demonstrated that it is a possibility. In a rat model of MI, injection of MSCs into the myocardium resulted in formation of ectopic bone [55]. Similarly, MSCs transplanted into a rat model of glomerulonephritis differentiated into adipose tissue [56]. Obviously, tumors and ectopic tissues would pose a serious danger to patients receiving MSC therapy, so if MSCs are indeed to be the cell type of the future, their safety must be unequivocally proven. In that case, the next step will be to establish a standardized dose and delivery method. This review has mentioned not only a variety of tissue origins for MSCs, but also three unique strategies for treatment: natural MSCs, growth factor primed cardiopoietic MSCs, and CMs differentiated from MSC-derived iPSCs. Though each method has shown promise, significant effort is still necessary to enable sustained restoration of the injured myocardium and elucidate the underlying biological mechanism.

\section{Acknowledgment}

The authors would like to acknowledge partial funding for this work through the Cardiovascular Cell Therapy Research Network (CCTRN) under cooperative agreement \#5UM1HL087318-08.

\section{References}

Papers of particular interest, published recently, have been highlighted as:

- Of importance

1. Go AS, Mozaffarian D, Roger VL, Benjamin EJ, Berry JD, Borden WB, et al. Executive summary: heart disease and stroke statistics-2013 update: a report from the American Heart Association. Circulation. 2013; 127(1):143-52. [PubMed: 23283859] 
2. Braunwald E, Pfeffer MA. Ventricular enlargement and remodeling following acute myocardial infarction: mechanisms and management. Am J Cardiol. 1991; 68(14):1D-6. [PubMed: 2058541]

3. Pfeffer MA, Braunwald E. Ventricular remodeling after myocardial infarction. Experimental observations and clinical implications. Circulation. 1990; 81(4):1161-72.

4. Sutton MG, Sharpe N. Left ventricular remodeling after myocardial infarction: pathophysiology and therapy. Circulation. 2000; 101(25):2981-8. [PubMed: 10869273]

5. Cohn JN, Ferrari R, Sharpe N. Cardiac remodeling - concepts and clinical implications: a consensus paper from an international forum on cardiac remodeling. J Am Coll Cardiol. 2000; 35(3):569-82. [PubMed: 10716457]

6. Lee TH, Hamilton MA, Stevenson LW, Moriguchi JD, Fonarow GC, Child JS, et al. Impact of left ventricular cavity size on survival in advanced heart failure. Am J Cardiol. 1993; 72(9):672-6. [PubMed: 8249843]

7. Loughran JH, Chugh AR, Ismail I, Bolli R. Stem cell therapy: promising treatment in heart failure? Curr Heart Fail Rep. 2013; 10(1):73-80. [PubMed: 23354783]

8. Beltrami AP, Barlucchi L, Torella D, Baker M, Limana F, Chimenti S, et al. Adult cardiac stem cells are multipotent and support myocardial regeneration. Cell. 2003; 114(6):763-76. [PubMed: 14505575]

9•. Friedenstein AJ, Piatetzky-Shapiro II, Petrakova KV. Osteogenesis in transplants of bone marrow cells. J Embryol Exp Morphol. 1966; 16(3):381-90. Research that led to the discovery of MSC and eventually their therapeutic properties. [PubMed: 5336210]

10. Friedenstein AJ, Chailakhjan RK, Lalykina KS. The development of fibroblast colonies in monolayer cultures of guinea-pig bone marrow and spleen cells. Cell Tissue Kinet. 1970; 3(4): 393-403. [PubMed: 5523063]

11. Friedenstein AJ, Chailakhyan RK, Gerasimov UV. Bone marrow osteogenic stem cells: in vitro cultivation and transplantation in diffusion chambers. Cell Tissue Kinet. 1987; 20(3):263-72. [PubMed: 3690622]

12. Owen M, Friedenstein AJ. Stromal stem cells: marrow-derived osteogenic precursors. Ciba Found Symp. 1988; 136:42-60. [PubMed: 3068016]

13. Caplan AI. Mesenchymal stem cells. J Orthop Res. 1991; 9(5):641-50. [PubMed: 1870029]

14. Murray IR, West CC, Hardy WR, James AW, Park TS, Nguyen A, et al. Natural history of mesenchymal stem cells, from vessel walls to culture vessels. Cell Mol Life Sci. 2013 Epub ahead of print.

15. Dominici M, Le Blanc K, Mueller I, Slaper-Cortenbach I, Marini FC, Krause DS, et al. Minimal criteria for defining multipotent mesenchymal stromal cells. The International Society for Cellular Therapy position statement. Cytotherapy. 2006; 8(4):315-7.

16. Caplan AI. Mesenchymal stem cells: cell-based reconstructive therapy in orthopedics. Tissue Eng. 2005; 11(7-8):1198-211. [PubMed: 16144456]

17. Caplan AI. Why are MSCs therapeutic? New data: new insight. J Pathol. 2009; 217(2):318-24. [PubMed: 19023885]

18. Toma C, Pittenger MF, Cahill KS, Byrne BJ, Kessler PD. Human mesenchymal stem cells differentiate to a cardiomyocyte phenotype in the adult murine heart. Circulation. 2002; 105(1): 93-8. [PubMed: 11772882]

19. Nakanishi C, Yamagishi M, Yamahara K, Hagino I, Mori H, Sawa Y, et al. Activation of cardiac progenitor cells through paracrine effects of mesenchymal stem cells. Biochem Biophys Res Commun. 2008; 374(1):11-6. [PubMed: 18586003]

20. Hatzistergos KE, Quevedo H, Oskouei BN, Hu Q, Feigenbaum GS, Margitich IS, et al. Bone marrow mesenchymal stem cells stimulate cardiac stem cell proliferation and differentiation. Circ Res. 2010; 107(7):913-22. [PubMed: 20671238]

21. Ranganath SH, Levy O, Inamdar MS, Karp JM. Harnessing the mesenchymal stem cell secretome for the treatment of cardiovascular disease. Cell Stem Cell. 2012; 10(3):244-58. [PubMed: 22385653]

22. Park CW, Kim K, Bae S, Son HK, Myung P, Hong HJ, et al. Cytokine secretion profiling of human mesenchymal stem cells by antibody array. Int J Stem Cells. 2009; 2(1):59-68. [PubMed: 24855521] 
23. Hoffmann J, Glassford AJ, Doyle TC, Robbins RC, Schrepfer S, Pelletier MP. Angiogenic effects despite limited cell survival of bone marrow-derived mesenchymal stem cells under ischemia. Thorac Cardiovasc Surg. 2010; 58(3):136-42. [PubMed: 20379963]

24. Watt SM, Gullo F, van der Garde M, Markeson D, Camicia R, Khoo CP, et al. The angiogenic properties of mesenchymal stem/stromal cells and their therapeutic potential. Br Med Bull. 2013; 108:25-53. [PubMed: 24152971]

25. Kim SW, Zhang HZ, Kim CE, Kim JM, Kim MH. Amniotic mesenchymal stem cells with robust chemotactic properties are effective in the treatment of a myocardial infarction model. Int $\mathrm{J}$ Cardiol. 2013; 168(2):1062-9. [PubMed: 23218573]

26. Weil BR, Manukyan MC, Herrmann JL, Abarbanell AM, Poynter JA, Wang Y, et al. The immunomodulatory properties of mesenchymal stem cells: implications for surgical disease. $\mathrm{J}$ Surg Res. 2011; 167(1):78-86. [PubMed: 20869073]

27. Chapel A, Bertho JM, Bensidhoum M, Fouillard L, Young RG, Frick J, et al. Mesenchymal stem cells home to injured tissues when co-infused with hematopoietic cells to treat a radiation-induced multiorgan failure syndrome. J Gene Med. 2003; 5(12):1028-38. [PubMed: 14661178]

28. Tomchuck SL, Zwezdaryk KJ, Coffelt SB, Waterman RS, Danka ES, Scandurro AB. Toll-like receptors on human mesenchymal stem cells drive their migration and immunomodulating responses. Stem Cells. 2008; 26(1):99-107. [PubMed: 17916800]

29. Chavakis E, Urbich C, Dimmeler S. Homing and engraftment of progenitor cells: a prerequisite for cell therapy. J Mol Cell Cardiol. 2008; 45(4):514-22. [PubMed: 18304573]

30. Shi Y, Hu G, Su J, Li W, Chen Q, Shou P, et al. Mesenchymal stem cells: a new strategy for immunosuppression and tissue repair. Cell Res. 2010; 20(5):510-8. [PubMed: 20368733]

31. Meirelles LS, Fontes AM, Covas DT, Caplan AI. Mechanisms involved in the therapeutic properties of mesenchymal stem cells. Cytokine Growth Factor Rev. 2009; 20(5-6):419-27. [PubMed: 19926330]

32. Gebler A, Zabel O, Seliger B. The immunomodulatory capacity of mesenchymal stem cells. Trends Mol Med. 2012; 18(2):128-34. [PubMed: 22118960]

33. Rasmusson I. Immune modulation by mesenchymal stem cells. Exp Cell Res. 2006; 312(12):216979. [PubMed: 16631737]

34. Squadrito F, Altavilla D, Squadrito G, Saitta A, Campo GM, Arlotta M, et al. Cyclosporin-A reduces leukocyte accumulation and protects against myocardial ischaemia reperfusion injury in rats. Eur J Pharmacol. 1999; 364(2-3):159-68. [PubMed: 9932719]

35. Raffaghello L, Bianchi G, Pistoia V. Immunosuppressive treatments in acute myocardial infarction and stroke. Curr Pharm Biotechnol. 2012; 13(1):59-67. [PubMed: 21470161]

36•. Hare JM, Traverse JH, Henry TD, Dib N, Strumpf RK, Schulman SP, et al. A randomized, double-blind, placebo-controlled, dose-escalation study of intravenous adult human mesenchymal stem cells (prochymal) after acute myocardial infarction. J Am Coll Cardiol. 2009; 54(24):2277-86. One of the first major clinical trials to prove the safety and efficacy of MSC therapy in cardiac repair. [PubMed: 19958962]

37. Telukuntla KS, Suncion VY, Schulman IH, Hare JM. The advancing field of cell-based therapy: insights and lessons from clinical trials. J Am Heart Assoc. 2013; 2(5):e000338. [PubMed: 24113326]

38. Hare JM, Fishman JE, Gerstenblith G, DiFede Velazquez DL, Zambrano JP, et al. Comparison of allogeneic vs autologous bone marrow-derived mesenchymal stem cells delivered by transendocardial injection in patients with ischemic cardiomyopathy: the POSEIDON randomized trial. JAMA. 2012; 308(22):2369-79. [PubMed: 23117550]

39. Bartunek J, Behfar A, Dolatabadi D, Vanderheyden M, Ostojic M, Dens J, et al. Cardiopoietic stem cell therapy in heart failure: the C-CURE (Cardiopoietic stem Cell therapy in heart failURE) multicenter randomized trial with lineage-specified biologics. J Am Coll Cardiol. 2013; 61(23): 2329-38. [PubMed: 23583246]

40. Houtgraaf JH, den Dekker WK, van Dalen BM, Springeling T, de Jong R, van Geuns RJ, et al. First experience in humans using adipose tissue-derived regenerative cells in the treatment of patients with ST-segment elevation myocardial infarction. J Am Coll Cardiol. 2012; 59(5):539-40. [PubMed: 22281257] 
41. Qayyum AA, Haack-Sorensen M, Mathiasen AB, Jorgensen E, Ekblond A, Kastrup J. Adiposederived mesenchymal stromal cells for chronic myocardial ischemia (MyStromalCell Trial): study design. Regen Med. 2012; 7(3):421-8. [PubMed: 22594332]

42. Houtgraaf JH, de Jong R, Kazemi K, de Groot D, van der Spoel TI, Arslan F, et al. Intracoronary infusion of allogeneic mesenchymal precursor cells directly after experimental acute myocardial infarction reduces infarct size, abrogates adverse remodeling, and improves cardiac function. Circ Res. 2013; 113(2):153-66. [PubMed: 23658436]

43•. Ge X, Wang IN, Toma I, Sebastiano V, Liu J, Butte MJ, et al. Human amniotic mesenchymal stem cell-derived induced pluripotent stem cells may generate a universal source of cardiac cells. Stem Cells Dev. 2012; 21(15):2798-808. Showed that iPSC derived from MSC could be used to generate immunoprivileged cardiac cells for transplantation. [PubMed: 22530853]

44. Takahashi K, Tanabe K, Ohnuki M, Narita M, Ichisaka T, Tomoda K, et al. Induction of pluripotent stem cells from adult human fibroblasts by defined factors. Cell. 2007; 131(5):861-72. [PubMed: 18035408]

45. Yamada S, Nelson T, Kane G, Martinez-Fernandez A, Crespo-Diaz RJ, Ikeda Y, et al. Induced pluripotent stem cell intervention rescues wall motion disparity achieving biological cardiac resynchronization post-infarction. J Physiol. 2013 Epub ahead of print.

46. Oskouei BN, Lamirault G, Joseph C, Treuer AV, Landa S, Da Silva J, et al. Increased potency of cardiac stem cells compared with bone marrow mesenchymal stem cells in cardiac repair. Stem Cells Transl Med. 2012; 1(2):116-24. [PubMed: 23197758]

47. Williams AR, Hatzistergos KE, Addicott B, McCall F, Carvalho D, Suncion V, et al. Enhanced effect of combining human cardiac stem cells and bone marrow mesenchymal stem cells to reduce infarct size and to restore cardiac function after myocardial infarction. Circulation. 2013; 127(2): 213-23. [PubMed: 23224061]

48. Rubio D, Garcia-Castro J, Martín MC, de la Fuente R, Cigudosa JC, Lloyd AC, et al. Spontaneous human adult stem cell transformation. Cancer Res. 2005; 65(8):3035-9. [PubMed: 15833829]

49. Rosland GV, Svendsen A, Torsvik A, Sobala E, McCormack E, Immervoll H, et al. Long-term cultures of bone marrow-derived human mesenchymal stem cells frequently undergo spontaneous malignant transformation. Cancer Res. 2009; 69(13):5331-9. [PubMed: 19509230]

50. Miura M, Miura Y, Padilla-Nash HM, Molinolo AA, Fu B, Patel V, et al. Accumulated chromosomal instability in murine bone marrow mesenchymal stem cells leads to malignant transformation. Stem Cells. 2006; 24(4):1095-103. [PubMed: 16282438]

51. Tolar J, Nauta AJ, Osborn MJ, Panoskaltsis Mortari A, McElmurry RT, Bell S, et al. Sarcoma derived from cultured mesenchymal stem cells. Stem Cells. 2007; 25(2):371-9. [PubMed: 17038675]

52. Barkholt L, Flory E, Jekerle V, Lucas-Samuel S, Ahnert P, Bisset L, et al. Risk of tumorigenicity in mesenchymal stromal cell-based therapies: bridging scientific observations and regulatory viewpoints. Cytotherapy. 2013; 15(7):753-9. [PubMed: 23602595]

53. Wong RS. Mesenchymal stem cells: angels or demons? J Biomed Biotechnol. 2011; 2011:459510. [PubMed: 21822372]

54. Bernardo ME, Fibbe WE. Safety and efficacy of mesenchymal stromal cell therapy in autoimmune disorders. Ann N Y Acad Sci. 2012; 1266:107-17. [PubMed: 22901262]

55. Breitbach M, Bostani T, Roell W, Xia Y, Dewald O, Nygren JM, et al. Potential risks of bone marrow cell transplantation into infarcted hearts. Blood. 2007; 110(4):1362-9. [PubMed: 17483296]

56. Kunter U, Rong S, Boor P, Eitner F, Müller-Newen G, Djuric Z, et al. Mesenchymal stem cells prevent progressive experimental renal failure but maldifferentiate into glomerular adipocytes. $\mathrm{J}$ Am Soc Nephrol. 2007; 18(6):1754-64. [PubMed: 17460140] 


\section{Opinion statement}

Owing to the prevalence of heart disease and the lack of effective long-term solutions for managing cardiac injury, research has turned to cell therapy as a potential mechanism for myocardial repair. Mesenchymal stem cells (MSC) in particular have become popular because their differentiative ability and their angiogenic and immunomodulatory properties make them attractive candidates for transplantation. However, there is still debate regarding the optimal strategy for the delivery of these cells. Recent clinical studies have isolated MSCs from a variety of tissue origins and have also tested the benefits of pretreatment with cardiogenic growth factors. Meanwhile, a newer school of thought instead supports the utilization of cardiomyocytes generated from MSC-derived induced pluripotent stem cells. This review will examine the promise of MSC therapy, discuss the results of past work, and propose steps that must be taken in the future. 